\title{
Perfil de imunoglobulinas, cura clínica e bacteriológica após diferentes tratamentos para a mastite clínica bovina
}

\author{
[Profile of immunoglobulins, clinical and bacteriological cure after different treatment routes of \\ clinical bovine mastitis] \\ M.G.B. Lima ${ }^{1}$, M.G. Blagitz ${ }^{1}$, F.N. Souza ${ }^{1 *}$, E.M.R. Sanchez ${ }^{1}$, C.F. Batista ${ }^{1}$, H.G. Bertagnon ${ }^{1,3}$,
S.A. Diniz ${ }^{2}$, M.X. Silva ${ }^{2}$, A.M.M.P. Della Libera \\ ${ }^{1}$ Universidade de São Paulo - São Paulo, SP \\ ${ }^{2}$ Universidade Federal de Minas Gerais - Belo Horizonte, MG \\ ${ }^{3}$ Universidade Centro Oeste do Paraná - UNICENTRO - Guarapuava, PR
}

\begin{abstract}
RESUMO
O presente estudo objetivou avaliar o perfil das Ig durante os diferentes tratamentos de vacas com mastite clínica. Para isso, 30 vacas com mastite clínica em um quarto mamário foram utilizadas e divididas em três grupos. O primeiro grupo foi composto por 10 animais submetidos ao tratamento combinado com infusão intramamária de $8,5 \mathrm{mg}$ de sulfato de cefquinoma após cada ordenha, totalizando três aplicações e administração intramuscular de $2,5 \mathrm{mg} / \mathrm{kg}$ de enrofloxacina por três dias. O segundo grupo foi composto por 10 animais submetidos ao tratamento intramamário, com infusão intramamária de 8,5mg de sulfato de cefquinoma, após cada ordenha, totalizando três aplicações. O terceiro grupo foi composto por 10 animais submetidos ao tratamento sistêmico, com $2,5 \mathrm{mg} / \mathrm{kg}$ de enrofloxacina, durante três dias. As amostras de leite foram coletadas de todos os animais antes dos tratamentos (momento 0), no segundo (momento 1), no quinto (momento 2) e no $12^{\circ}$ dia (momento 3) após o término dos tratamentos. Estas foram submetidas à contagem de células somáticas, ao California Mastitis Test (CMT), ao exame bacteriológico e à quantificação das $\operatorname{IgG}_{1}, \operatorname{IgG}_{2}, \operatorname{Ig} A$ e IgM. O tratamento combinado foi mais eficaz e precoce na taxa de cura clínica, na redução dos escores de CMT e da contagem de células somáticas. Além disso, os resultados do presente estudo demonstraram que as concentrações lácteas das diferentes classes de Ig, apesar de sua importância biológica, não estão relacionadas ao prognóstico da mastite clínica bovina, ou seja, não podem ser consideradas marcadores robustos associados à cura clínica e/ou bacteriológica da infecção intramamária.
\end{abstract}

Palavras-chave: terapia, infecção intramamária, imunidade humoral, contagem de células somáticas, vaca leiteira

\begin{abstract}
The present study aimed to evaluate the profile of immunoglobins profile, clinical and bacteriological cure after different treatment routes of clinical bovine mastitis. Here, 30 Holstein cows with clinical mastitis in one quarter were uniformly divided into: 10 dairy cows that received $8.5 \mathrm{mg}$ of cefquinome sulphate administrated intramammarily during three consecutive milkings and $2.5 \mathrm{mg} / \mathrm{kg}$ of enrofloxacin administrated parenterally during three consecutive days (Group 1); 10 dairy cows that received 8.5mg of cefquinome sulphate administrated intramammarily during three consecutive milkings (Group 2); and 10 dairy cows that received $2.5 \mathrm{mg} / \mathrm{kg}$ of enrofloxacin administrated parenterally during three consecutive days (Group 3). Milk samples for somatic cell count, California Mastitis Test (CMT), bacteriological culture and quantification of $\operatorname{Ig} G_{1}, \operatorname{Ig} G_{2}, \operatorname{IgM}$ and $\operatorname{IgA}$ were collected before antimicrobial treatment, and after two, five and 12 days after the antimicrobial treatment. The combined treatment was more effective
\end{abstract}

Recebido em 16 de janeiro de 2017

Aceito em 5 de agosto de 2017

*Autor para correspondência (corresponding author)

E-mail: nogueirasouza@yahoo.com.br 
in the clinical cure rate, reduction of somatic cell count and CMT scores. Furthermore, the results demonstrated that milk concentration of different Igs classes were not related to prognosis of bovine clinical mastitis, and then cannot be considered as robust markers associated with clinical and bacteriological cures.

Keywords: therapy, intramammary infection, humoral immunity, somatic cell count, dairy cow

\section{INTRODUÇÃOO}

A mastite é a enfermidade mais comum em vacas leiteiras e a de maior impacto econômico. Compromete a produção e a qualidade do leite, sendo responsável pela maior porcentagem do uso de antimicrobianos em rebanhos leiteiros (Stevens et al., 2016). As mastites podem ser classificadas em mastite subclínica, quando não há alterações macroscópicas detectáveis na glândula mamária, ou em mastite clínica, que apresenta sinais clínicos evidentes, como alterações no leite, úbere ou animal (Sadek et al., 2017).

Componentes da imunidade humoral, como as imunoglobulinas (Ig), desempenham papel importante na defesa da glândula mamária bovina (Burton e Erskine, 2003; Boerhout et al., 2016). A produção de Ig em quantidade suficiente no local da infecção é um importante mecanismo do sistema imunológico para aumentar a fagocitose e, portanto, para a eliminação de patógenos intramamários (Leitner et al., 2000). Durante o processo inflamatório, além da produção de $\operatorname{IgA}$ e $\operatorname{IgM}$ na glândula mamária, as $\operatorname{IgG}_{1}$ e $\operatorname{IgG}_{2}$ migram da corrente sanguínea para a glândula mamária. As $\operatorname{IgM}$ e $\mathrm{IgG}_{2}$ funcionam como anticorpos opsonizantes para os leucócitos polimorfonucleares (PMN) de bovinos, que auxiliam na prevenção da colonização bacteriana (Paape et al., 2003), enquanto a $\operatorname{IgA}$ neutraliza as toxinas bacterianas (Kehrli e Harp, 2001). Assim, supõe-se que, durante o tratamento da mastite, é possível avaliar o perfil das Ig como possível prognóstico da doença pela cura clínica e bacteriológica dos quartos mamários afetados.

Além disso, a motivação do presente estudo foi encontrada diante do grande desafio que a bovinocultura de leite enfrenta contra a mastite, entre elas o fracasso nos tratamentos e a diversidade dos protocolos terapêuticos. Nesse cenário de avaliação da cura clínica, sem percepção do prognóstico antes do tratamento e respectiva cura bacteriológica, os motivos de insucesso ficam obscuros e devem ser analisados precocemente. Portanto, a finalidade principal do presente estudo não foi avaliar isoladamente a resposta do tratamento propriamente dita, mas identificar a resposta imune humoral adotada pelo animal diante da doença.

Alguns estudos realizados buscaram responder a eficiência dos diferentes tratamentos na cura da mastite clínica e bacteriológica das infecções intramamárias (Sérieys et al., 2005; Pyöräla, 2009). Outros buscaram avaliar o perfil das Ig durante processos infecciosos causados por agentes específicos (Leitner et al., 2000; Boerhout et al., 2016). Até o momento, nenhum estudo buscou avaliar o perfil das Ig diante de diferentes tratamentos da mastite clínica bovina, como foi realizado no presente estudo.

Portanto, o objetivo do presente estudo foi avaliar o perfil das Ig diante de diferentes tratamentos de mastite clínica bovina. Além disso, investigou-se a cura clínica e bacteriológica após o tratamento da mastite clínica por via intramamária, sistêmica e combinada.

\section{MATERIAL E MÉTODOS}

Foram selecionadas 30 vacas da raça Holandesa, criadas em sistema de produção intensivo, submetidas a duas ordenhas diárias, diagnosticadas com mastite clínica em um quarto mamário pelo exame da caneca de fundo escuro (FE). Esses animais foram divididos aleatoriamente, independentemente do agente etiológico, em três grupos experimentais, que foram tratados conforme descrito a seguir: G1) tratamento combinado - constituído por 10 animais, que foram tratados com infusão intramamária de $8,5 \mathrm{mg}$ de sulfato de cefquinoma (Cobactan ${ }^{\circledR}$ VL, MSD Saúde Animal, Cruzeiro, Brasil) após cada ordenha, totalizando três aplicações, e administração intramuscular de $2,5 \mathrm{mg} / \mathrm{kg}$ de enrofloxacina (Flotril 10\%, MSD Saúde Animal, Cruzeiro, Brasil), por três dias, conforme preconizado por Shpigel et al. (1997); G2) tratamento intramamário - constituído por 
10 animais, que foram tratados com infusão intramamária de $8,5 \mathrm{mg}$ de sulfato de cefquinoma (Cobactan ${ }^{\circledR}$ VL, MSD Saúde Animal, Cruzeiro, Brasil), após cada ordenha, totalizando três aplicações, conforme recomendado por Swinkels et al. (2013); G3) tratamento sistêmico constituído por 10 animais, que foram tratados com 2,5mg/kg de enrofloxacina (Flotril 10\%, MSD Saúde Animal, Cruzeiro, Brasil), durante três dias, conforme descrito por Hoeben et al. (2000).

Antes dos tratamentos, as amostras de leite foram coletadas individualmente do quarto mamário afetado para análises laboratoriais (momento 0 M0). As amostras de leite foram coletadas no segundo (momento $1-\mathrm{M} 1$ ), no quinto (momento $2-\mathrm{M} 2$ ) e no $12^{\circ}$ dia (momento 3 - M3) após o término dos tratamentos, conforme descrito por Shpigel et al. (1997). Em todos os grupos e momentos, foram realizados o exame do fundo escuro do leite, o California Mastitis Test (CMT), o exame bacteriológico do leite, a contagem automática de células somáticas e a quantificação de $\operatorname{IgG} 1, \operatorname{IgG} 2, \operatorname{Ig} \mathrm{A}$ e $\operatorname{IgM}$.

O estudo foi aprovado pelo Comitê de Ética de Uso de Animais da Faculdade de Medicina Veterinária e Zootecnia da Universidade de São Paulo, sob o número de protocolo 2435/2011.

Para o exame bacteriológico, foi realizada a antissepsia do orifício do teto com algodão embebido em álcool 70\%, seguido do descarte dos três primeiros jatos de leite para posterior coleta das amostras de leite dos quartos mamários diagnosticados com mastite clínica em frascos estéreis (aproximadamente $3 \mathrm{~mL}$ ). As amostras foram mantidas a $4^{\circ} \mathrm{C}$ até a chegada ao laboratório e armazenadas a $-20^{\circ} \mathrm{C}$ até a realização das análises até o máximo 30 dias após a coleta. No laboratório, $0,01 \mathrm{~mL}$ das amostras de leite foi semeado em placas com 5\% de ágar sangue de carneiro desfibrinado e MacConkey. As placas foram incubadas a $37^{\circ} \mathrm{C}$, por 24 a 72 horas. Em seguida, a morfologia das colônias foi observada e foram realizados a coloração de Gram e o teste de catalase. Em cocos Gram-positivos e catalase negativo, foi realizado o teste de coagulase. Cocos Grampositivos e catalase negativo foram identificados como Streptococcus spp. Cocos Gram-positivos e catalase positivo foram identificados como Staphylococcus spp. As colônias Gram-positivos e a catalase positivo e com formato de bastonete, visíveis após 48 horas de incubação, foram classificadas como Corynebacterium spp.

As CCS do leite coletadas com bronopol (2bromo-2-nitropane-1,3-diol) foram realizadas utilizando-se o contador automático de células somáticas Somacount 300 (Bentley Instruments, Chaska, EUA). Para o teste do CMT, foi utilizado detergente púrpura de bromocresol ( $2 \mathrm{~mL}$ do reagente em $2 \mathrm{~mL}$ de leite), observandose a intensidade da reação (aumento da viscosidade da mistura leite e reagente) e variações do $\mathrm{pH}$. Os resultados do CMT foram classificados em: 0) nenhum precipitado; 1) precipitado distinto/formação de gel fraca; 2) formação de gel distinta; ou 3) formação de gel forte (Della Libera et al., 2011).

As amostras de leite também foram coletadas em frascos cônicos de $50 \mathrm{~mL}$ e processadas de acordo com as recomendações de Koess e Hamann (2008) e o sobrenadante foi congelado a $-80^{\circ} \mathrm{C}$ para posterior quantificação de Ig. A quantificação de Ig foi realizada por ensaio de imunoabsorção enzimática (ELISA) utilizandose kits comerciais para quantificação de $\operatorname{IgG}_{1}$ (Bovine $\mathrm{IgG}_{1}$ ELISA, Quantitation Set, Bethyl Laboratories Inc., Montgomery, EUA), $\mathrm{IgG}_{2}$ (Bovine $\mathrm{IgG}_{2}$ ELISA, Quantitation Set, Bethyl Laboratories Inc., Montgomery, EUA), IgA (Bovine IgA ELISA, Quantitation Set, Bethyl Laboratories Inc., Montgomery, EUA) e IgM (Bovine IgM ELISA, Quantitation Set, Bethyl Laboratories Inc., Montgomery, EUA), de acordo com as recomendações do fabricante. As diluições das amostras de leite foram: $\mathrm{IgG}_{1}$ 1:50.000, $\mathrm{IgG}_{2}-1: 300.000, \operatorname{IgA}-1: 500 \mathrm{e}$ 1:4.000 e IgM - 1:1.000, conforme descrito por Wilson et al. (2007) e Ploegart et al. (2011).

Foi considerada cura clínica quando o quarto mamário afetado com mastite clínica não apresentou sinais clínicos evidentes na glândula mamária nem alterações das características do leite detectados no FE nos momentos citados acima (até $12^{\circ}$ dia após término do tratamento), considerando-se que qualquer episódio com até 14 dias após a detecção da mastite clínica é classificado como o mesmo caso de mastite clínica (Barkema et al., 1998). Foi considerada cura bacteriológica quando o agente etiológico (gênero bacteriano) da mastite clínica isolado das amostras de leite coletadas do quarto mamário 
anterior ao tratamento não foi isolado e identificado nas amostras de leite coletadas do mesmo quarto mamário 12 dias após o término do tratamento.

Inicialmente, as distribuições de todas as variáveis foram examinadas utilizando-se gráficos de probabilidade normal obtidos pelos testes de Shapiro e Wilk. Os dados de FE e exame bacteriológico foram classificados em escore zero (negativo) e um (positivo). Os dados foram inicialmente analisados por análise de variância multivariada. Os dados de CCS foram transformados em $\log _{10}$ e analisados pela ANOVA, seguido pelo teste de Duncan. Para os demais dados, utilizou-se o teste de KruskalWallis. As análises estatísticas foram realizadas mediante o uso do software estatístico STATA, versão 12 (Stata Corp., College Station, Texas,
EUA). Os resultados estão demonstrados como média \pm erro-padrão. Para todos os resultados, foram consideradas significativas as análises que apresentaram $\mathrm{P} \leq 0,05$.

\section{RESULTADOS}

Os resultados do FE, do CMT, da celularidade e do isolamento bacteriano estão descritos nas Tab. 1,2 e 3. Os dados do FE, do CMT e do exame bacteriológico foram classificados em escores. Houve cura clínica em 100\%, 90\% e 90\% nos G1, G2 e G3, respectivamente, não sendo observada diferença estatística entre os tratamentos (Tab. 1). Observou-se cura bacteriológica em $87,5 \%, 66,67 \%$ e $75,0 \%$ nos G1, G2 e G3, respectivamente.

Tabela 1. Média e erro-padrão da média da CCS e dos escores dos exames do fundo escuro e CMT

\begin{tabular}{ccccc}
\hline & & \multicolumn{3}{c}{ Grupos } \\
\cline { 3 - 4 } & & G1 & G2 & G3 \\
\hline \multirow{2}{*}{ FE } & Momento 0 & $1,00( \pm 0,00)^{\mathrm{Aa}}$ & $1,00( \pm 0,00)^{\mathrm{Aa}}$ & $1,00( \pm 0,00)^{\mathrm{Aa}}$ \\
& Momento 1 & $0,00( \pm 0,00)^{\mathrm{Ba}}$ & $0,40( \pm 0,52)^{\mathrm{Ba}}$ & $0,20( \pm 0,42)^{\mathrm{Ba}}$ \\
& Momento 2 & $0,00( \pm 0,00)^{\mathrm{Ba}}$ & $0,00( \pm 0,00)^{\mathrm{Ba}}$ & $0,10( \pm 0,32)^{\mathrm{Ba}}$ \\
& Momento 3 & $0,00( \pm 0,00)^{\mathrm{Ba}}$ & $0,10( \pm 0,32)^{\mathrm{Ba}}$ & $0,10( \pm 0,32)^{\mathrm{Ba}}$ \\
& Momento 0 & $3,20( \pm 0,42)^{\mathrm{Aa}}$ & $3,50( \pm 0,53)^{\mathrm{Aa}}$ & $3,20( \pm 0,42)^{\mathrm{Aa}}$ \\
\hline & Momento 1 & $1,60( \pm 0,97)^{\mathrm{Bb}}$ & $2,70( \pm 0,48)^{\mathrm{Aa}}$ & $1,60( \pm 1,07)^{\mathrm{Bb}}$ \\
& Momento 2 & $1,10( \pm 1,20)^{\mathrm{Ba}}$ & $1,50( \pm 0,97)^{\mathrm{Ba}}$ & $1,40( \pm 0,84)^{\mathrm{Ba}}$ \\
& Momento 3 & $0,40( \pm 0,52)^{\mathrm{Cb}}$ & $0,80( \pm 0,92)^{\mathrm{Bab}}$ & $1,70( \pm 0,82)^{\mathrm{Ba}}$ \\
& Momento 0 & $6,60( \pm 0,19)^{\mathrm{Aa}}$ & $6,82( \pm 0,19)^{\mathrm{Aa}}$ & $6,53( \pm 0,19)^{\mathrm{Aa}}$ \\
\hline & Momento 1 & $5,98( \pm 0,19)^{\mathrm{Ba}}$ & $6,56( \pm 0,19)^{\mathrm{ABa}}$ & $6,51( \pm 0,19)^{\mathrm{Aa}}$ \\
& Momento 2 & $5,42( \pm 0,19)^{\mathrm{BCb}}$ & $6,02( \pm 0,19)^{\mathrm{Ba}}$ & $6,48( \pm 0,19)^{\mathrm{Aa}}$
\end{tabular}

Letras minúsculas diferentes indicam diferenças entre colunas $(\mathrm{P} \leq 0,05)$.

Letras maiúsculas diferentes indicam diferenças entre linhas $(\mathrm{P} \leq 0,05)$.

$\log _{10}$ CCS: analisados utilizando-se ANOVA, seguido pelo teste de Duncan.

FE e CMT: teste de Kruskal-Wallis.

G1: tratamento combinado intramamário e sistêmico (sulfato de cefquinoma + enrofloxacina); G2: tratamento intramamário (sulfato de cefquinoma); G3: tratamento sistêmico (enrofloxacina); M0: anterior ao tratamento; M1: segundo dia após o final do tratamento; M2: quinto dia após o final do tratamento; M3: $12^{\circ}$ dia após o final do tratamento; FE: fundo escuro; CMT: California Mastitis Test; CCS: contagem de células somáticas. 
Tabela 2. Média e erro-padrão da média do escore do exame bacteriológico

\begin{tabular}{cccc} 
& \multicolumn{3}{c}{ Grupos } \\
\cline { 2 - 4 } & G1 & G2 & G3 \\
\hline M0 & $0,80( \pm 0,42)^{\mathrm{Aa}}$ & $0,30( \pm 0,48)^{\mathrm{Aa}}$ & $0,40( \pm 0,52)^{\mathrm{Aa}}$ \\
M1 & $0,10( \pm 0,32)^{\mathrm{Ba}}$ & $0,00( \pm 0,00)^{\mathrm{Aa}}$ & $0,50( \pm 0,53)^{\mathrm{Aa}}$ \\
M2 & $0,20( \pm 0,42)^{\mathrm{Bab}}$ & $0,10( \pm 0,32)^{\mathrm{Ab}}$ & $0,70( \pm 0,48)^{\mathrm{Aa}}$ \\
M3 & $0,20( \pm 0,42)^{\mathrm{Ba}}$ & $0,30( \pm 0,48)^{\mathrm{Aa}}$ & $0,70( \pm 0,48)^{\mathrm{Aa}}$ \\
\hline
\end{tabular}

Letras minúsculas diferentes indicam diferenças entre colunas $(\mathrm{P} \leq 0,05)$.

Letras maiúsculas diferentes indicam diferenças entre linhas $(\mathrm{P} \leq 0,05)$.

Exame bacteriológico: teste de Kruskal-Wallis.

G1: tratamento combinado intramamário e sistêmico (sulfato de cefquinoma + enrofloxacina); G2: tratamento intramamário (sulfato de cefquinoma); G3: tratamento sistêmico (enrofloxacina); M0: anterior ao tratamento; M1: segundo dia após o final do tratamento; M2: quinto dia após o final do tratamento; M3: $12^{\circ}$ dia após o final do tratamento.

Tabela 3. Porcentagem de isolamento bacteriano nas amostras de leite nos diferentes momentos: anterior e após o tratamento

\begin{tabular}{|c|c|c|c|}
\hline & \multicolumn{3}{|c|}{ Grupos } \\
\hline & G1 & $\mathrm{G} 2$ & G3 \\
\hline M0 & $\begin{array}{c}2(20 \%) \text { Negativas } \\
7(70 \%) \text { Streptococcus spp. } \\
1(10 \%) \text { Staphylococcus spp. }\end{array}$ & $\begin{array}{c}7(70 \%) \text { Negativas } \\
3(30 \%) \text { Streptococcus spp. }\end{array}$ & $\begin{array}{c}6(60 \%) \text { Negativas } \\
4(40 \%) \text { Streptococcus spp. }\end{array}$ \\
\hline M1 & $\begin{array}{c}9(90 \%) \text { Negativas } \\
1(10 \%) \text { Streptococcus spp. }\end{array}$ & $10(10 \%)$ Negativas & $\begin{array}{c}5(50 \%) \text { Negativas } \\
5(50 \%) \text { Streptococcus spp. }\end{array}$ \\
\hline M2 & $\begin{array}{c}8(80 \%) \text { Negativas } \\
2(20 \%) \text { Streptococcus spp. }\end{array}$ & $\begin{array}{c}9(90 \%) \text { Negativas } \\
1(10 \%) \text { Streptococcus spp. }\end{array}$ & $\begin{array}{c}3(30 \%) \text { Negativas } \\
6(60 \%) \text { Streptococcus spp. } \\
1(10 \%) \text { Corynebacterium spp. }\end{array}$ \\
\hline M3 & $\begin{array}{c}8(80 \%) \text { Negativas } \\
1(10 \%) \text { Streptococcus spp. } \\
1(10 \%) \text { Staphylococcus spp. }\end{array}$ & $\begin{array}{c}7(70 \%) \text { Negativas } \\
2(20 \%) \text { Streptococcus spp. } \\
1(10 \%) \text { Corynebacterium spp. }\end{array}$ & $\begin{array}{c}3(30 \%) \text { Negativas } \\
6(60 \%) \text { Streptococcus spp. } \\
1(10 \%) \text { Corynebacterium spp. }\end{array}$ \\
\hline
\end{tabular}

G1: tratamento combinado intramamário e sistêmico (sulfato de cefquinoma + enrofloxacina); G2: tratamento intramamário (sulfato de cefquinoma); G3: tratamento sistêmico (enrofloxacina); M0: anterior ao tratamento; M1: segundo dia após o final do tratamento; M2: quinto dia após o final do tratamento; M3: $12^{\circ}$ dia após o final do tratamento.

O escore do CMT no M1 foi menor nos quartos mamários dos animais submetidos ao tratamento combinado e ao tratamento sistêmico do que naqueles que receberam tratamento antimicrobiano por via intramamária (Tab. 1). Dessa forma, o escore do CMT dos quartos mamários das vacas que receberam tratamento antimicrobiano combinado e por via sistêmica já diminuiu significantemente em M1, enquanto o escore do CMT nos quartos mamários que receberam tratamento antimicrobiano reduziu significantemente apenas em M2. Os animais submetidos ao tratamento combinado no M3 apresentaram menor escore do CMT do que os animais que receberam tratamento antimicrobiano por via sistêmica (Tab. 1).

A CCS nos animais que receberam o tratamento antimicrobiano combinado foi menor no M2 do que os grupos dos animais tratados com medicamento intramamário ou sistêmico isoladamente (Tab. 1). No grupo submetido ao tratamento combinado, observou-se maior celularidade no M0 do que nos M1, M2 e M3, e 
o M1 apresentou maior celularidade do que o M3 (Tab. 1). A celularidade dos quartos mamários que receberam tratamento antimicrobiano por via intramamária foi menor em M2 e M3 que em M0 (Tab. 1). Não foram observadas diferenças entre os momentos no grupo de animais submetidos ao tratamento sistêmico (Tab. 1).

As quantificações de $\operatorname{IgM}, \operatorname{Ig} A, \operatorname{IgG}_{1}$ e de $\operatorname{IgG}_{2}$ estão demonstradas na Tab. 4. Os animais que foram tratados pela via sistêmica apresentaram no M3 maior concentração láctea de IgM do que os animais do grupo tratado por via intramamária. Os animais do grupo combinado apresentaram menor concentração láctea de $\operatorname{IgM}$ no M3 do que nos M0, M1 e M2. Os animais submetidos ao tratamento intramamário apresentaram maior concentração láctea de $\operatorname{IgM}$ nos M0 e M1 do que no M3, e maior concentração de $\operatorname{IgM}$ no M1 do que no M2. Não foram observadas diferenças no grupo submetido ao tratamento sistêmico. As concentrações lácteas de $\operatorname{IgA}, \operatorname{IgG}_{1}$ e $\operatorname{IgG}_{2}$ não diferiram entre os momentos nos três grupos experimentais.

Tabela 4. Média e erro-padrão da média das concentrações lácteas de $\operatorname{IgM}, \operatorname{IgA}, \operatorname{IgG}_{1}$ e $\operatorname{IgG}_{2}$

\begin{tabular}{|c|c|c|c|c|}
\hline & & \multicolumn{3}{|c|}{ Grupos } \\
\hline & & G1 & $\mathrm{G} 2$ & G3 \\
\hline \multirow[t]{4}{*}{$\operatorname{IgM}(\mathrm{mg} / \mathrm{dL})$} & Momento 0 & $17,72( \pm 8,11)^{\mathrm{Aa}}$ & $14,82( \pm 10,40)^{\mathrm{ABa}}$ & $13,67( \pm 6,46)^{\mathrm{Aa}}$ \\
\hline & Momento 1 & $78,02( \pm 195,09)^{\mathrm{Aa}}$ & $19,03( \pm 10,60)^{\mathrm{Aa}}$ & $11,88( \pm 3,28)^{\mathrm{Aa}}$ \\
\hline & Momento 2 & $11,36( \pm 2,67)^{\mathrm{Aa}}$ & $11,07( \pm 6,04)^{\mathrm{BCa}}$ & $11,16( \pm 5,18)^{\mathrm{Aa}}$ \\
\hline & Momento 3 & $9,82( \pm 5,94)^{\mathrm{Bab}}$ & $8,03( \pm 8,21)^{\mathrm{Cb}}$ & $13,80( \pm 8,74)^{\mathrm{Aa}}$ \\
\hline \multirow[t]{4}{*}{$\operatorname{IgA}(\mathrm{mg} / \mathrm{dL})$} & Momento 0 & $46,75( \pm 63,98)^{\mathrm{Aa}}$ & $16,90( \pm 24,19)^{\mathrm{Ab}}$ & $59,91( \pm 46,66)^{\mathrm{Aa}}$ \\
\hline & Momento 1 & $63,86( \pm 82,62)^{\mathrm{Aab}}$ & $23,23( \pm 22,68)^{\mathrm{Ab}}$ & $60,12( \pm 63,31)^{\mathrm{Aa}}$ \\
\hline & Momento 2 & $20,17( \pm 16,62)^{\text {Aab }}$ & $17,99( \pm 23,82)^{\mathrm{Ab}}$ & $54,60( \pm 64,37)^{\mathrm{Aa}}$ \\
\hline & Momento 3 & $25,16( \pm 20,78)^{\mathrm{Aa}}$ & $49,78( \pm 68,96)^{\mathrm{Aa}}$ & $52,32( \pm 42,44)^{\mathrm{Aa}}$ \\
\hline \multirow[t]{4}{*}{$\operatorname{IgG}_{1}(\mathrm{mg} / \mathrm{dL})$} & Momento 0 & $122,97( \pm 84,94)^{\mathrm{Aa}}$ & $152,07( \pm 82,77)^{\mathrm{Aa}}$ & $130,67( \pm 96,64)^{\mathrm{Aa}}$ \\
\hline & Momento 1 & $105,00( \pm 143,75)^{\mathrm{Aa}}$ & $158,94( \pm 84,88)^{\mathrm{Aa}}$ & $85,41( \pm 50,74)^{\mathrm{Aa}}$ \\
\hline & Momento 2 & $124,43( \pm 164,89)^{\mathrm{Aa}}$ & $106,55( \pm 36,63)^{\mathrm{Aa}}$ & $89,69( \pm 52,29)^{\mathrm{Aa}}$ \\
\hline & Momento 3 & $207,74( \pm 285,01)^{\mathrm{Aa}}$ & $92,29( \pm 55,41)^{\mathrm{Aa}}$ & $105,88( \pm 53,35)^{\mathrm{Aa}}$ \\
\hline \multirow[t]{4}{*}{$\mathrm{IgG}_{2}(\mathrm{mg} / \mathrm{dL})$} & Momento 0 & $100,89( \pm 176,14)^{\mathrm{Aa}}$ & $9,93( \pm 25,37)^{\mathrm{Ab}}$ & $13,29( \pm 13,52)^{\mathrm{Aab}}$ \\
\hline & Momento 1 & $11,01( \pm 12,08)^{\mathrm{Aa}}$ & $1,39( \pm 0,62)^{\mathrm{Ab}}$ & $9,03( \pm 7,31)^{\mathrm{Aab}}$ \\
\hline & Momento 2 & $11,81( \pm 13,54)^{\mathrm{Aa}}$ & $1,18( \pm 0,65)^{\mathrm{Ab}}$ & $10,77( \pm 8,83)^{\mathrm{Aa}}$ \\
\hline & Momento 3 & $21,87( \pm 37,89)^{\mathrm{Aa}}$ & $1,18( \pm 0,69)^{\mathrm{Ab}}$ & $11,64( \pm 9,47)^{\mathrm{Aa}}$ \\
\hline
\end{tabular}

Letras minúsculas diferentes indicam diferenças entre colunas $(\mathrm{P} \leq 0,05)$.

Letras maiúsculas diferentes indicam diferenças entre linhas $(\mathrm{P} \leq 0,05)$.

Igs: teste de Kruskal-Wallis.

G1: tratamento combinado intramamário e sistêmico (sulfato de cefquinoma + enrofloxacina); G2: tratamento intramamário (sulfato de cefquinoma); G3: tratamento sistêmico (enrofloxacina); IgM: imunoglobulina M; IgA: imunoglobulina $\mathrm{A}$; $\mathrm{IgG}_{1}$ : imunoglobulina $\mathrm{G}_{1} ; \mathrm{IgG}_{2}$ : imunoglobulina $\mathrm{G}_{2} ; \mathrm{M} 0$ : anterior ao tratamento; $\mathrm{M} 1$ : segundo dia após o final do tratamento; M2: quinto dia após o final do tratamento; M3: $12^{\circ}$ dia após o final do tratamento. 
Além disso, a concentração láctea de $\operatorname{IgA}$, IgM e $\mathrm{IgG}_{2}$ em M0 e M1 nos quartos mamários que apresentaram cura clínica $(n=24)$ em M1 não foi estatisticamente diferente (dados não demonstrados) quando comparada com a dos quartos mamários que não apresentaram cura clínica $(n=6 ; M 1)$. No entanto, constatou-se uma tendência à maior concentração láctea de $\operatorname{IgG}_{1}$ $(\mathrm{P}=0,08)$ no $\mathrm{M} 1$ nos quartos mamários que não obtiveram a cura clínica $(172,3 \pm 106,0 \mathrm{mg} / \mathrm{dL})$ nesse mesmo momento (Fig. 1) quando comparados com os quartos mamários que não apresentaram cura clínica no M1 $(102,5 \pm 98,6)$.

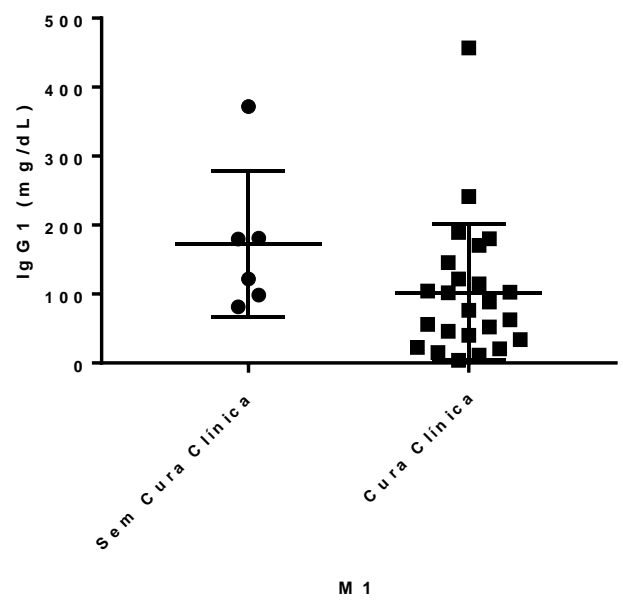

Figura 1. Concentrações de imunoglobulina $G_{1}$ láctea nos quartos mamários que apresentaram ou não cura clínica, independentemente do tratamento, dois dias após o término do tratamento (M1).

\section{DISCUSSÃO}

O tratamento combinado foi mais eficaz e precoce na redução da CCS e do escore do CMT. Isso provavelmente se deve ao fato que o uso de tratamentos combinados pode resultar em maior concentração dos antimicrobianos no leite e nos tecidos mamários. Por outro lado, a concentração de antimicrobianos administrados por via intramamária pode não proporcionar a adequada concentração dos princípios ativos no parênquima mamário mais profundo por período de tempo suficiente para eliminar a infecção. Dessa forma, acredita-se que a infusão intramamária proporciona o contato do antimicrobiano com a bactéria em crescimento nas cisternas da glândula e dos grandes ductos, e que a administração sistêmica poderia funcionar de forma sinérgica devido ao contato com tecidos mais profundos (Owens e Nickerson, 1989). Entretanto, o uso de tratamentos combinados pode resultar em dosagens dos princípios ativos mais altas do que as recomendadas, o que pode levar a resíduos de antimicrobianos no leite superiores ao período esperado (Barkema et al., 2006), além de elevar os custos com o tratamento. Ademais, apesar de não ter sido observada diferença estatística entre os tratamentos na cura clínica, $10 \%$ dos animais dos grupos tratados por via intramamária ou sistêmica apresentaram mastite clínica no $12^{\circ}$ dia após o fim do tratamento, enquanto nenhum animal manifestou mastite clínica no grupo que recebeu tratamento combinado pelas vias intramamária e sistêmica.

No presente estudo, os resultados obtidos não corroboraram a hipótese de que as concentrações lácteas das distintas classes de Ig estariam relacionadas com o prognóstico da mastite clínica bovina. Em bovinos, assim como em murinos e humanos, a produção de interferon- $\gamma$ está relacionada à resposta imune celular (Th1) que favorece a produção de $\mathrm{IgG}_{2}$ (Burton e Erskine, 2003). Por outro lado, na resposta imune Th2, há predomínio de interleucina (IL)-4 e IL10 e produção de $\operatorname{IgM}$ e $\operatorname{IgG}_{1}$, bem como menor recrutamento de PMN para a glândula mamária (Burton e Erskine, 2003). Nesse contexto, observou-se tendência à maior concentração de $\mathrm{IgG}_{1}$, que está relacionada à resposta $\mathrm{Th} 2$, apesar de não ter apresentado diferença significativa 
entre os grupos, dos quartos mamários que não apresentaram cura clínica - independentemente do grupo experimental - quando comparados com os quartos mamários que apresentaram cura clínica dois dias após o tratamento antimicrobiano (Fig. 1). Sob outro aspecto, a $\mathrm{IgG}_{2}$ está relacionada à resposta celular Th1 e, apesar de não ter sido observada diferença estatística, o que foi provavelmente associado à alta dispersão dos dados, foi numericamente maior nos quartos mamários com cura clínica em M1 (49,39 $\pm 120,0 \mathrm{mg} / \mathrm{dL})$ quando comparados com os quartos mamários que não apresentaram cura clínica em M1 $(9,28 \pm 12,76 \mathrm{mg} / \mathrm{dL})$. Tais resultados indicam a importância da resposta imune celular (Th1) na defesa da glândula mamária, com a resolução do processo inflamatório agudo local. Isso denota a relevância da polarização da resposta imune para a resposta imune celular Th1 diante de um processo inflamatório na glândula mamária para a resolução desse processo (Burton e Erskine, 2003).

No leite, a principal Ig opsonizadora para os PMN de bovinos é a $\mathrm{IgG}_{2}$ (Burton e Erskine, 2003; Paape et al., 2003). Por exemplo, ao contrário da $\operatorname{IgM}$ e da $\operatorname{IgG}_{1}$, as Ig da subclasse $\mathrm{IgG}_{2}$ não precisam da fixação de complemento para desenvolverem atividades de opsoninas (Rainard et al., 1988). Desse modo, o sincronismo de IgG2 e o influxo de neutrófilos são fundamentais para que os neutrófilos recéminfiltrados na glândula mamária infectada atuem de forma efetiva pela fagocitose das bactérias invasoras previamente opsonizadas. Nesse ínterim, sabe-se que o pico de $\mathrm{IgG}_{2}$ no leite ocorre quatro horas após o início do processo infeccioso, ou seja, seis a 12 horas anteriormente ao pico de infiltração de neutrófilos do sangue para a glândula mamária (Burton e Erskine, 2003). Portanto, não é por acaso que animais que eliminam novas infecções intramamárias apresentam altas concentrações de $\mathrm{IgG} 2$ específicas e um rápido e massivo recrutamento de neutrófilos para o sítio inflamatório (Burton e Erskine, 2003).

Além disso, no presente estudo, independentemente do tratamento, observou-se maior concentração de $\mathrm{IgG}_{2}$ no momento que antecede os tratamentos $(41,37 \pm 19,76 \mathrm{mg} / \mathrm{dL}$ em M0), a qual, logo após, decai significantemente $(11,57 \pm 4,27 \mathrm{mg} / \mathrm{dL} \quad$ em $\mathrm{M} 3 ; \quad \mathrm{P}=0,008)$, diferentemente da $\mathrm{IgG}_{1}(135,2+15,73 \mathrm{mg} / \mathrm{dL}$ em M0 e 135,3mg/dL $+31,51$ em $\mathrm{M} 3 ; \mathrm{P}=0,23)$. Isso corrobora estudos que demonstraram que as concentrações de $\operatorname{IgG}_{2}$ no leite sem mastite são extremamente baixas e, por conseguinte, a atividade de opsonização em leite de glândulas saudáveis é igualmente muito baixa (Burton e Erskine, 2003). Assim, diante do processo infeccioso, a $\mathrm{IgG}_{2}$ auxilia a fagocitose de neutrófilos presentes no leite de glândulas mamárias infectadas (Leitner et al., 2000; Paape et al., 2003) e os neutrófilos no leite expressam receptores Fc para $\operatorname{IgG}_{2}$ (Paape et al., 2003). Em contraste, os neutrófilos no leite não expressam receptores $F c$ para anticorpos $\operatorname{IgG}_{1}$ e $\operatorname{IgA}$ (Paape et al., 2003). Ademais, durante o processo migratório de leucócitos para a glândula mamária, principalmente de neutrófilos, ocorre a indução da expressão de receptores quimiotáticos para as $I g G_{2}$ e M e o CR1 - receptor do sistema complemento (Paape et al., 2003).

\section{CONCLUSÕES}

O tratamento combinado foi mais eficaz e precoce na taxa de cura clínica, na redução da CCS e no escore de CMT. Além disso, os resultados do presente estudo demonstraram que as concentrações lácteas das diferentes classes de Ig, apesar de sua importância biológica, não estão relacionadas ao prognóstico da mastite clínica bovina, ou seja, não podem ser consideradas marcadores robustos associados à cura clínica e/ou bacteriológica da infecção intramamária.

\section{AGRADECIMENTOS}

Este estudo foi desenvolvido com o auxílio à pesquisa da Fundação de Amparo à Pesquisa do Estado de São Paulo (Fapesp; processo $\mathrm{n}^{\mathbf{o}}$. 2012/00008-9). Alice Maria Melville Paiva Della Libera e Fernando Nogueira de Souza agradecem pelas bolsas concedidas pelo Conselho Nacional de Desenvolvimento Científico e Tecnológico (CNPq) e pela Fapesp, respectivamente. 


\section{REFERÊNCIAS}

BARKEMA, H.W.; SCHUKKEN, Y.H.; ZADOKS, R.N. Invited review: the role of cow, pathogen, and treatment reginen in the therapeutic success of bovine Staphylococcus aureus mastitis. J. Dairy Sci., v.89, p.1877-1895, 2006.

BARKEMA, H.W.; SHUKKEN, Y.H.; LAM, T.J. et al. Incidence of subclinical mastitis in dairy herds grouped in three categories of bulk milk somatic cell counts. J. Dairy Sci., v.81, p.411-419, 1998.

BOERHOUT, E.M.; KOETS, A.P.; VERNOOIJ, J.C.M. et al. Reisolation of Staphylococcus aureus from bovine milk following experimental inoculation is influenced by fat percentage and specific immunoglobulin G1 titer in milk. J. Dairy Sci., v.99, p.4259-4269, 2016.

BURTON, J.L.; ERSKINE, R.J. Immunity and mastitis. Some new ideas for an old disease. Vet. Clin. N. Am. Food A, v.19, p.1-45, 2003.

DELLA LIBERA, A.M.M.P.; SOUZA, F.N.; BLAGITZ, M.G.; BATISTA, C.F. Avaliação de indicadores inflamatórios no diagnóstico da mastite bovina. Arq. Inst. Biol., v.78, p.297-300, 2011.

HOEBEN, D.; MONTFARDINI, E.; BURVENICH, C.; HAMANN, J. Treatment of acute Escherichia coli mastitis in cows with enrofloxacin: effect on clinical symptoms and chemiluminescence of circulating neutrophils. J. Dairy Res., v.67, p.485-502, 2000.

KEHRLI, M.; HARP, J. Immunity in the mammary gland. Vet. Clin. N. Am. Food A, v.17, p.495-516, 2001.

KOESS, C.; HAMANN, J. Detection of mastitis in the bovine mammary gland by flow cytometry at early stages. J. Dairy Res., v.75, p.225-232, 2008.

LEITNER, G.; YADLIN, B.; GLICKMAN, A. et al. Systemic and local immune response of cows to intramammry infection with Staphylococcus aureus. Res. Vet. Sci., v.69, p.181-184, 2000.

OWENS, W.E.; NICKERSON, S.C. Antibiotic levels in milk and mammary tissue during various treatment regimens for bovine mastitis. Agric. Pract., v.10, p.1015, 1989.
PAAPE, M.J.; BANNERMAN, D.D.; ZHAO, X.; LEE, J.W. The bovine neutrophil: structure and function in blood and milk. Vet. Res., v.34, p.597-627, 2003

PLOEGART, T.C.W.; TIJHAAR, E.; LAM, T.J.G.M. et al. Natural antibodies in bovine milk and blood plasma: variability among cows, repeatability within cows, and relation between milk and plasma titers. Vet. Immunol. Immunopathol., v.144, p.88-94, 2011.

PYÖRÄLA, S. Treatment of mastitis during lactation. Irish Vet. J., v.62, p.40-44, 2009.

RAINARD, P.; LAUTROU, Y.; POUTREL, B. Ingestion and killing of Streptococcus agalactiae by bovine granulocytes in the presence of natural opsonins. Vet. Microbiol., v.18, p.41-50, 1988.

SADEK, K.; SALEH, E.; AYOUB, M. Selective, reliable blood and milk bio-markers for diagnosing clinical and subclinical bovine mastitis. Trop. Anim. Health Prod., v.49, p.431-437, 2017.

SÉRIEYS, F.; RAGUET, Y.; GOBY, L.; SCHMIDT, $\mathrm{H}$. Comparative efficacy of local and systemic antibiotic treatment in lactating cow with clinical mastitis. J. Dairy Sci., v.88, p.93-99, 2005.

SHPIGEL, N.Y.; DLEVIN, D.; WINKLER, M. et al. Efficacy of cefquinome for treatment of cows with mastitis experimentally induced using Escherichia coli. J. Dairy Sci., v.80, p.318-323, 1997.

STEVENS, M.; PIEPERS, S.; SUPRÉ, K. et al. Quantification of antimicrobial consumption in adult cattle on dairy herds in Flanders, Belgium, and associations with udder health, milk quality, and production performance. J. Dairy Sci., v.99, p.21182130, 2016

SWINKELS, J.M.; COX, P.; SCHUKKEN, Y.H.; LAM, T.J.G.M. Efficacy of extended cefquinome treatment of clinical Sthaphylococcus aureus mastitis. J. Dairy Sci., v.96, p.4983-4992, 2013.

WILSON C.D.J.; MALLARD, B.A.; BURTON, J.L.; SCHUKKEN, Y. Milk and serum J5 - specific antibody responses, milk production change, and clinical effects following intramammary Escherichia coli challenge for J5 vaccinate and control cows. Clin. Vaccine Immunol., v.14, p.693-699, 2007. 